John J. Skowronski

Northern Illinois University

Constantine Sedikides

University of Southampton

In R. Dunbar \& L. Barrett (Eds.). Oxford Handbook of Evolutionary Psychology. Oxford, UK.

Corresponding Author:

John J. Skowronski

Department of Psychology

Northern Illinois University

DeKalb, IL 60115

USA

Email: jskowron@niu.edu 


\section{Temporal Knowledge and Autobiographical Memory: An Evolutionary Perspective}

One characteristic of humans is that they have a sense of self. Exactly what does this mean? Examination of research and theory exploring the psychology of the self suggests that it has at least three important aspects.

The first of these aspects is representation: The memory system contains mental structures that store and organize different kinds of self-relevant knowledge. Some of this knowledge is affective, reflecting the feelings that people have about themselves. Also, some of the knowledge is behavioral, reflecting mental procedures that contain memories of how to carry out various routines (e.g., riding a bicycle). This procedural information is often stored in non-verbal form. In addition, some of the knowledge reflects episodic memories of specific life events. These memories contain perceptual details of events, as well as information about event contexts (e.g., the time at which an event occurred). Furthermore, some of the knowledge is semantic, reflecting memories of self-judgments or the judgments that others have made of, and conveyed to, the self. These selfjudgments can be global (e.g., I am an uncoordinated person) or situationally constrained (e.g., I am good at cooking Indian food). These semantic representations can also contain memories of meta-cognitions (e.g., ideas about how others perceive one's behavior), information referring to dyadic relationships, information about one's position within a group, and information about intragroup dynamics and intergroup relations. Moreover, these semantic representations might contain information about how one compares to others or to the groups to which one belongs. Such information highlights those attributes that make one unique and distinct from attributes that characterize others (personal self), 
those attributes that are shared with others with whom one has interpersonal relations (relational self), or those attributes that one shares with the groups to which one belongs (collective self) (Sedikides \& Brewer, 2001).

The second attribute of the human self is that it maintains an executive function, regulating an individual's relation with the social and physical environment. Three classes of motives likely guide this capacity (Sedikides \& Skowronski, 2000; Sedikides, Skowronski, \& Gaertner, 2004): valuation (i.e., protecting and enhancing the self), learning (i.e., pursing a relatively accurate image of the self, improving skills and abilities), and homeostasis (i.e., seeking and endorsing information that is consistent with the self).

The third attribute of the self is reflexivity. This term can be defined as the organism's ability to depict itself in its ongoing relation with other objects. Reflexivity is manifested in the interplay between the representational and executive capacities. For example, reflexivity allows the organism to alter long-term goals and render them congruent with anticipated environmental changes. This ability to reflect on the self also involves the capacity for humans to engage in mental time travel. That is, humans can remember (or, more accurately, use their knowledge to reconstruct) specific events in the past, and can have some knowledge of the time and the place at which those events occurred. Humans can also reflect on their role in future events and engage in alternative mental simulations of future events in which the nature of those events, an individual's role in those events, and each event's outcome can be manipulated.

In previous writings (Sedikides \& Skowronski, 1997, 2000, 2003; Sedikides, 
Skowronski, \& Dunbar, in press; Sedikides et al. 2004; Skowronski \& Sedikides, 1999), we discussed these aspects of the self in the context of evolution. Our argument has been that these self-aspects developed in response to the environmental challenges that were encountered by the ancestors of the human species and by early humans. These environmental challenges included not only the pressures imposed by the physical environment (e.g., food procurement, climate, predation), but also the pressures imposed by the social and cultural context of human behavior.

\section{Temporal Knowledge in the Context of Evolution}

The present chapter will recapitulate some of these themes in the context of the ability of humans to remember events in their lives at specific points in time. We do so with some trepidation, for the study of time and memory has a long intellectual history. For example, in his Confessiones, penned early in the fourth century, Saint Augustine (Book XI, see Haddan's 1872 translation) derived the then-radical conclusion that perceptions of time itself (or, at least, perceptions of the past and of the future) are things that are contained in the mind. Augustine was largely concerned with the estimation of durations; the length of time events happened or the length of time between events. This interest in event durations significantly influenced early scientific psychological theorizing (James, 1890) and is reflected in the modern discipline of mental chronobiology (Bradshaw \& Szabadi, 1997).

However, the ability to make these duration judgments presupposes the ability to know how long ago the beginning of an event (or when a prior event) occurred. Thus, in order to understand duration estimates, psychologists need to know how an individual 
knows the age of events. Whereas event-specific temporal knowledge has not been studied as thoroughly as duration perceptions, it too has a long intellectual history (Hoffding, 1885; James, 1890; Sturt, 1925) and has recently been the subject of intense empirical scrutiny (Friedman, 2004; Hoerl \& McCormack, 2001).

Why might the ability to know the time at which an event occurred, or the event's age, be important to humans? One reason lies in the fact that humans have a self-concept, and many elements of this self-concept incorporate, or require the use of, at least some event-specific temporal knowledge. For example, an individual's sense of growth and change comes from their ability to know when events occurred in their lives. How can one draw any conclusions about progress in one's ability in a given domain if one cannot properly order recollections of the early episodes of struggle and the later episodes of accomplishment? More generally, just imagine how incomplete one's sense of self might be without the ability to temporally locate autobiographical events. Given this line of argument, it seems reasonable to argue that, to understand the self, one must understand the nature of one's ability to remember events in their temporal context.

The evolutionary twist to this idea is the argument that the capacity to develop a self-concept may have been a product of evolution (Sedikides \& Skowronski, 1997, 2000, 2003; Sedikides et al., in press). That is, the capacity to think about the self in an abstract manner was likely an adaptive response to the environmental pressures faced by both the species that were ancestors to modern humans and the early members of the human species. The possession of a self-concept can endow the possessor with several rewards, ranging from advantages in food procurement, predation avoidance, and 
interpersonal relations with other group members. We extend this line of reasoning by taking an evolutionary perspective on an organism's ability to remember when an event or behavior occurred. We argue that being able to store temporally-relevant information and being able to retrieve and use that information to determine the time at which an event occurred has adaptive value to a species.

What might that adaptive value be? Being sensitive to temporal information can improve the fit between an organism and the environmental niche that the organism occupies. For example, many organisms have the ability to remember the time of day at which given sources of food are available (Gallistel, 1990). Similar kinds of temporal sensitivity may guide the instigation of migratory behaviors, as well as times in which an individual chooses to be relatively inactive. Such inactivity minimizes energy use at lowpayoff times or helps to protect an organism from predation. In short, in many circumstances time is one of the discriminative cues that an organism uses to optimize its behavior in a given environment. It matters for an organism to be sensitive to, and use, temporal information.

One element of this sensitivity to time is the ability to store temporal information in, and retrieve it from, memory. This can be accomplished in several ways. One might build temporal sensitivity into an organism in such a way that the temporal stimulus is a relatively automatic trigger for behavior. One hypothetical example is activity level. For some organisms, when light levels fall below a given threshold, the neural system may automatically instigate behavior inactivity. A second way in which an organism can be sensitive to temporal information is via some sort of conceptual or rule-based knowledge. 
For example, an individual organism may have developed abstract concepts allowing differentiation among different types of flowers, and might come to learn that a given type of flower is good to visit when the sun goes down because that is when the flowers open and make the flowers' sweet-tasting nectar available. This does not require memory for specific flower visits. It requires only the realization that a given flower type, visited at a given time, is likely to yield a food reward. A third way in which an organism can be sensitive to temporal information occurs when temporal information is stored as a part of memories for specific episodes. For example, an organism might remember that a given river contained many fish when the river was visited at a particular time of day and in a particular season. Such event-based recollections might induce the organism to visit that river again at that same time during that same season.

These sources of temporal knowledge correspond to the three different types of knowledge (anoetic, noetic, and autonoetic) that can be stored in memory and that may comprise different memory subsystems (Tulving, 1985). This distinction, too, is of potential evolutionary importance. Some scholars have argued that not all organisms share these different knowledge systems, and that some systems are more characteristic of organisms that have particularly large and differentiated brains that can perform numerous specialized and complex thinking tasks. For example, Suddendorf and Corballis (1997) suggest that the ability to remember single specific episodes from one's past is a relatively recent evolutionary development, relying on the ability to think about oneself in abstract terms. In their view, the fact that the self has the property of reflexivity is what allows humans so easily to think about past behaviors and events that occur at a 
particular time and in a particular place. The produce of this reflexive thinking can then be stored in memory. Hence, in the view of Suddendorf and Corballis, the ability to have episodic memories can only occur once an organism has acquired the capacity to think about oneself abstractly (e.g., as a symbolic self; Sedikides \& Skowronski, 1997). Their thesis, then, is that there can be no memory for individual events without a functional self-concept.

We disagree with this thesis. Both reason and data suggest to us that the ability to represent and use recalled event-specific information (including temporal information) evolved independently of the capacity to form and use a symbolic self. Instead, we propose that the evolution of a symbolic self depends, in part, on the prior ability to mentally represent the details of specific life events. Hence, we would expect to observe evidence that the ability to know the time at which events occurred emerged earlier in evolution and was a more widespread adaptation compared to the ability to form a symbolic self.

In evaluating this proposal, one must first consider whether the ability to recall the temporal context of specific life episodes itself could be an adaptation driven by evolution. Friedman (2001) argues that the ability to remember the temporal context of specific episodes may not have much adaptive potential. Instead, he argues that the ability to remember information relevant to the typical time cycles that are important to an organism's environmental niche is a more likely candidate for the action of natural selection. We disagree. Rather, we maintain that, in many circumstances, it can be very adaptive for an organism to have even approximate knowledge of when a past event 
occurred or when a prior action was performed.

Consider, for example, animals who engage in food-caching behavior. Some cached foods are relatively impervious to decay (e.g., nuts). Other types of food are relatively decay-prone. If an organism is to make efficient use of time in retrieving food from multiple caches, then it would be useful if the organism could remember how long ago a given food item was cached - especially if the animal has the ability to learn that some foods spoil when stored for long periods of time.

This is not a hypothetical example. Griffiths, Dickinson, and Clayton (1999; also see de Kort, Dickinson, \& Clayton, 2005) trained jays in a task in which the jays cached either worms or peanuts in two separate sand-filled trays. The birds were given the opportunity to learn that the worms decayed and were inedible 124 hours after caching, but that the peanuts were still edible. After training, the jays were later presented with a task in which one food was cached in one side of a tray and, 120 hours later, the other food was cached on the other side of the tray. Four hours later, the jays were allowed to forage in the tray. When the worms were the first food cached (124 hours ago), the jays preferentially searched for peanuts. This did not occur when the worms were the second food cached (four hours ago). Such behavior required that the jays remembered what they had hidden, where they had hidden it, and how long ago it was hidden. The jays' use of all of these kinds of information would seem to be hallmarks of memories for specific episodes.

However, as we will note later in this chapter, the behavior of the jays does not necessarily imply that they had specific memories for each of the caching events. Several 
theorists (Roberts, 2002; Suddendorf \& Corballis, 1997) have claimed that other, nonevent specific memory information might be responsible for the jays' ability to remember how long ago a food was cached. At the moment, more important for our purposes is the idea that memory for an event's age can sometimes have adaptive value for an organism, and hence, is potentially an attribute that can be evolutionarily selected.

The ability to locate events in time is not solely restricted to jays. For example, Schwartz, Hoffman, and Evans (2005) have conducted studies with King, an adult male western lowland gorilla. The results of these studies showed that King's behavior reflected episodic-like memory properties, in that King could remember the order of past events (Experiment 1) and could remember where events occurred (Experiment 2).

In our view, the generality of such findings across species is an important fact favoring an evolutionary genesis of the ability to locate events in time. In fact, we would be quite surprised if this ability were solely the purview of humans. It has often been said that evolution is a tinkerer, and works by taking old characteristics and modifying them. Hence, it seems sensible that one would find the precursors of temporal knowledge abilities, or simple versions of a temporal knowledge system, in those species that are relatively close to humans on the bush of evolution. Moreover, because nature often reuses solutions, when species confront similar environmental pressures, evolution often comes up with similar responses to those pressures. Hence, even species that are distantly related may come to share similar traits because of the extent to which those traits aid adaptiveness to the similar environments shared by those species. This suggests that, if 
the ability to remember temporal knowledge is an adaptation, then it may be shared by many species that inhabit similar environments.

Obviously, the adaptive value of temporal knowledge will be particularly high for species whose environments continually present problems that can be best solved if one has access to the temporal context of past events and behaviors. Humans are one of these species. For example, a crucial motive that drives human behavior is self-enhancement (Sedikides \& Gregg, 2003; Sedikides \& Strube, 1997). One of the hallmarks of selfenhancement is the perception of personal growth - that one has improved one's status or abilities from where one was in the past. Development and maintenance of veridicality in such self-judgments relies on the ability to remember what one was like at various points in the past. We do not claim that humans are perfect in this regard-peoples' recollections of what they were like at various points in the past can be biased in many ways (Cameron, Wilson, \& Ross, 2004). Instead, our main point is that pursuit of selfenhancement is promoted by the ability to perceive improvement from one's prior state. In order to do that, one will need to have at least an approximate sense of the point in time at which that prior state existed.

The ability to remember the temporal context of events may be particularly critical to knowledge in the social domain. In previous work (Sedikides \& Skowronski, 1997, 2003), we have argued that the line of evolution that yielded modern humans was likely to have occurred in a relatively unstructured social context. This unstructured social context resembles modern human behavior, in which alliances form, shift, disengage, and reform with a relatively high frequency. Optimal functioning in such an 
environment would seem to be facilitated if organisms were able to keep track of who had done what with whom (or to whom) at different specific times in the past. Such knowledge would likely help individuals to make better decisions about interpersonal behavior. For example, if you recall that one group member was a cheater (e.g., hoarded provisions) in his early days, but has not engaged in such behavior recently, you might be more likely to trust that individual than when you could not remember the times at which that individual had cheated or had been honest.

Another example might concern decisions about paternity in a species (e.g., humans) that does not maintain exclusivity in sexual partners. For example, if a female had sex with one individual 15 months ago, with a second individual 8 months ago, and with a third individual 2 months ago, the female needs to recall the age of those encounters reliably to infer the paternity of the infant to whom she just gave birth. Evolution-driven paternity concerns are paramount for females who invest large amounts of time and effort in their young (Sagarin, 2005). Hence, it would seem beneficial if the new mother could accurately recall the time at which intercourse with each partner was initiated so that paternity could be definitively established.

\section{On Humans' Ability to Remember When}

Up to this point in the chapter, we have discussed humans' ability to place personal life events in time in an abstract manner. However, we believe that it would be beneficial if some time were spent reviewing a few specific findings pertaining to this ability. These findings can be particularly enlightening with respect to the kinds of information that are used when individuals attempt to place events in time, and can help 
clarify some important questions with respect to the possible evolution of the capacity to store and retrieve temporal knowledge.

Results of a good deal of temporal judgment research suggest that temporal knowledge becomes less accurate with increases in time from the target event. For example, in several studies conducted in the laboratory of one of this chapter's co-authors (Skowronski, Betz, Thompson, \& Larsen, 1995; Thompson, Skowronski, \& Lee, 1988a), participants entered events in a dated diary, then later attempted to reproduce the date when cued with each event (Thompson, Skowronski, Larsen, \& Betz, 1996). Participants could report an autobiographical event's exact date often ( $70 \%$ of the time) if an event was a week old. However, by the time an autobiographical event was ten weeks old, the exact accuracy rate of event dating dropped substantially (e.g., 20\% accuracy rate). Another way to depict increasing inaccuracy across time is to calculate the extent to which the average amount of error associated with event date estimates increases over time. In studies reported by Thompson et al. (1996), that amount was approximately one day per week of event age. That is, estimates of event dates that were ten weeks old evinced an approximate average of 10 days of error; events that were 20 weeks old evinced an approximate average of 20 days or error, etc.

A second consistent pattern, also illustrated by the abovementioned findings, is that participants do not often recall the exact time at which an event occurred. In the Thompson et al. (1996) investigation, even when events were only 10 weeks old, and even when participants had the advantage of writing the events in a dated diary, participants could still date only one in five events with exact accuracy. Friedman (1987) 
reported that this paucity of event-specific temporal memory was evidenced across multiple time frames: Participants in his study infrequently reported exact temporal knowledge about events, regardless of whether one asked about the month in which an event occurred, the day of the month, the day of the week, or the hour of the day.

The accumulating data also suggest a relationship between memory for an event's content and the accuracy of event dating: The better an event is remembered, the more accurate the temporal estimate provided for the event. For example, in several studies (Skowronski, Betz, Thompson, \& Shannon, 1991; Betz \& Skowronski, 1997), participants provided ratings of how well they remembered autobiographical events, as well as providing event dates. Self-rated memory strength was significantly related to the accuracy of the temporal estimates that were provided by participants. That this should occur is obvious - if one recalls that an event occurred when snow was on the ground, one would probably suspect that the event occurred in winter. Participants' self-reports of the process by which they obtained event dates fit with this notion. They indicated that they did sometimes use their ability to remember event details to reconstruct the time at which an event occurred.

The notion that event dates are reconstructed leaves open the possibility that those reconstructions can be biased. Indeed, many such biases have been identified. These biases often reflect the influence of abstract real-world knowledge on temporal judgments. For example, one bias occurs due to the presence of a bounded time period specifying the starting and ending points between which events must have occurred. Many of the studies conducted in this line of research used such bounded periods - 
typically the beginning and end of academic terms. The presence of such boundaries produced telescoping effects in the date estimates (Thompson, Skowronski, \& Lee, 1988b). When the events were recent, the events were misdated in the direction of being older than they were (backward telescoping); when the events were old, the events were misdated in the direction of being younger then they were (forward telescoping). The telescoping effects reflect the impact of landmark boundaries on those guesses: Dating errors drift toward the middle of the period defined by the boundaries (Rubin \& Baddeley, 1989).

Errors in dating observed by Thompson, Skowronski, and Betz (1993) provided additional evidence for the use of landmarks to construct date estimates. One typical landmark event is the start of a connected event sequence, such as the start of a vacation. To estimate the dates of all the same-vacation events listed in one's diary, one simply has to establish the date of the initial event and subsequently date all the vacation events relative to that initially dated landmark. However, if the first event is misdated, then the remaining events would be misdated by exactly the same amount of time. Thompson et al. (1993) showed that there were frequent "error runs" in the date estimates: Clusters of similarly-misdated events (e.g., a series of events on 5 consecutive days, all of which were misdated by 7 days) occurred at a rate greater than that expected by chance.

One other consistently observed finding is that, when temporal information is reconstructed, the reconstructions often use available information that can operate on relatively independent multiple time scales. For example, Skowronski et al. (1991) first showed that error frequencies in date estimates showed a peculiar "scalloping" pattern: 
The most frequent errors in date estimates were at multiples of seven days $(7,14,21$, etc.). Such error patterns reflect the fact that a standard blank calendar that included day of the week was used to cue participants' date estimates (Gibbons \& Thompson, 2001), and that participants had day-of the week knowledge available to them that was cued by these day-of-week labels. Hence, the calendar might prompt people to recall that an event happened on a Tuesday, but not which Tuesday.

Betz and Skowronski (1997) elaborated on this finding. They showed that participants were more likely to make dating errors within particular day-of-week segments than between day-of-week segments. For example, it was relatively likely that a person would misdate a Saturday event (e.g., attending a nephew's soccer match) as occurring on a Sunday; but it was relatively less likely that the person would misdate that event as occurring on a Tuesday. They argued that these findings followed from topdown knowledge about the nature of events that occur within a given week. That is, for many people, weeks are temporally segmented into subunits: a typical segmentation is weekend versus weekday. Hence, when trying to reconstruct the date in which an event occurred, people may be able to place it in a week subsegment (e.g., a weekend event), but not the exact day within that subsegment. Thus, misdating errors are likely to occur for days within a given subsegment, but not between subsegments.

Many of the findings described in the preceding paragraphs point to the notion that substantial reconstruction is needed to establish the time at which an event occurred. The effortful nature of such reconstructions seemed to be confirmed by the subjective responses of participants in the Thompson-Skowronski event dating studies. The process 
of determining event dates was subjectively difficult for many of these individuals (e.g., they often complained about the difficulty of the task), and it typically took participants a long time to complete the dating task.

However, not all temporal knowledge needs to be so painstakingly reconstructed. For example, some studies exploring temporal knowledge ask participants to judge the order in which two events occurred. Response accuracy and latency are commonly recorded in such studies (Skowronski, Walker, \& Betz, 2003; Skowronski, Ritchie, Walker, Betz, Sedikides, Bethencourt et al., 2006). One outcome of such studies is $a$ temporal distance effect: Controlling for the ages of the events that are involved, the farther apart in age the two events are, the easier (faster, more accurate) the judgment becomes. This temporal distance effect is inconsistent with the notion that event age estimates are obtained with great difficulty. Instead, for events that are far apart in age, event order judgments are made with great speed and accuracy. This suggests that there is some characteristic of event representations that allows rapid identification of rudimentary forms of temporal knowledge.

In fact, when viewed through a different lens, many of the studies in the Thompson-Skowronski program of research can also be viewed as supportive of such mechanisms. For example, even though the error magnitudes associated with event date estimates increased substantially with an event's age, it was nonetheless the case that the average of the date estimates across participants often approximated an event's real age. Thus, though erroneous, the event dates were not random guesses - participants' responses often reflected some temporal knowledge. This rough level of accuracy 
emerged even when participants indicated that the event date that they provided was not a product of reconstruction, but was it was just a guess.

On the basis of his research with children, Friedman (2001) came to a similar conclusion about the fact that some temporal knowledge may not come from elaborate temporal reconstructions. He reviewed the results of several studies suggesting that young children have the ability to know approximate event ages (at least up to a point), despite being unable to engage in relatively sophisticated temporal reconstructive strategies.

Possible sources of rough information about an event's age come from the characteristics of a memory: its accessibility or its vividness, for example. The stronger the memory, or the more easily it comes to mind, the more recent the event. In fact, although not voluminous, the literature already provides some evidence for the operation of such mechanisms (Bradburn, Rips, \& Shevell, 1987).

A second possibility is that autobiographical events are linked to semantic information that has temporal implications (Conway \& Pleydell-Pearce, 2000). That is, there may be a "header" or "tag" linked to an event that identifies the broad period in which the event occurred. This tag could be "graduate school" or "my first job" or "when I was a kid.” When events are separated by long periods of time, temporal discriminations may be easy because the temporal orderings are specified by the tags ("when I was a kid" comes before "graduate school"). When events are relatively close in time, such time-discriminating event tags may not be present and people may need repeatedly to access fine-grained event knowledge in their attempt to determine event 
orders. Such repeated access is difficult, which would be indicated by responses that take a long time and are often incorrect. Recent research (Skowronski et al., 2006) has confirmed this prediction.

Another possibility lies in the fact that the self-concept can serve as a context for memory (Skowronski, Walker, \& Edlund, 2006). When recalling an autobiographical event, one's recollection might include memories about self - both external characteristics and abilities as well as internal states and traits. For example, when reminded about scoring a game-winning goal, one might bring to mind that she or he was insecure because or a recent move to a new town, was small in physical stature in comparison to other players on the team, and had just mastered a new bicycle kick that allowed the goal to be scored. This activated self-image can serve as a "rough and ready" cue that helps to place an event in temporal context. Thus, one might be able roughly to place an event in time by comparing the self-image activated by event recall to one's current self-image. Self-images that are highly discrepant imply old events; self-images that are congruent imply recent events. Similarly, when trying to decide which of two events is more recent, the event that prompts recall of a self-image that is more discrepant from the current self is the event that will be judged to be older.

One final possibility is that some form of temporal information is encoded when events are stored in memory. For example, Brown, Preece, and Hulme (2000) suggest the presence of an array of neural-array oscillators that work at different frequencies. The state of the array at any given moment is a learning context that can become a part of the stored memory for a given experience. Generally speaking, the greater the temporal 
distance between two events, the greater the difference in the values output by the oscillator array. Hence, one should theoretically be able to determine how long ago events occurred by examining the state of the oscillator information that was encoded with a given memory and comparing it to the current oscillator state. Likewise, the oscillator states of two retrieved memories could be used to determine the relative recency of two recalled events. Such knowledge need not be explicitly accessed, but can instead be an implicit part of the memory system (Brown \& Chater, 2001). Hence, when this mechanism is operative people may simply "know" the relative times of events without the need for extensive reconstruction.

These oscillator models of temporal knowledge have several advantages. One is that they can be mathematically modelled, as Brown et al. (2000) have done for their OSCAR model. A second advantage is that, because such models do not involve the operation of higher-order cognitive processes, they can also be applied to the data derived from non-humans. Indeed, as noted earlier in this chapter, a large corpus of knowledge suggests that animals are sensitive to time and often behave as though they had access to event-specific temporal knowledge associated with specific event memories. For example, after being fed at different locations at different times of day, pigeons learn to anticipate where they will get fed (Saksida \& Wilke, 1994). Also, animals can make recency judgments between two events: To obtain a reward in a conditional discrimination task, animals can respond to a stimulus array by choosing the stimulus that was presented most recently (Zentall, 2005). 
However, the application of the Brown et al. (2000) oscillator model mechanisms to animal temporal judgments would seem to assume that animals possess an episodic memory (see McCormack, 2001, p. 292 for a similar argument). Whether or not nonhuman animals possess this type of memory system has been the subject of much recent debate. The nature of various memory systems, their potential contributions to temporal knowledge, and the potential existence of these memory systems across species are topics that are treated in the next section.

The Types of Memory That Contribute to Knowledge of an Event's Age

Obviously, attempts at establishing the time at which an event occurred require that an individual have some form of memory. But what kind of memory? We mentioned previously the distinction among three levels of knowing: anoetic (non-knowing), noetic (knowing) and autonoetic (self-knowing) (Tulving, 1985). Anoetic knowledge reflects the traces of experience that are unknowable to the knower. Psychology abounds with demonstrations of this kind of knowledge. For example, studies of subliminal priming show that individuals' responses to the world around them can be influenced by stimuli presented outside the level of conscious awareness (Stapel \& Koomen, 2005). In comparison, noetic knowledge reflects one's knowledge about the world. For example, people know that babies are small in size and that dogs are often kept as pets. Finally, autonoetic knowledge reflects memory for one's own personal experiences, such as the time one of this chapter's co-authors was stuck in the airport in Rome.

The empirical evidence indicates that these three types of knowledge reflect different memory systems with different neural substrates (Buckner \& Schacter, 2004). 
Some of the more exotic findings involve patients with various forms of amnesia. These often take the form of dissociations in which only one of the three memory systems seems to show impairment. The distinction between anoetic knowledge and the other two forms of knowledge is indicated by the fact that some patients, such as the famous H.M., lost the ability to remember past experiences but were clearly influenced by those experiences (Ogden \& Corkin, 1991). Other patients show seeming dissociations in their ability to remember information about the world in general and in their ability to recall specific events. For example, semantic dementia is primarily a disease in which semantic memory is compromised (Hodges, Patterson, Oxbury, \& Funnell, 1992). Patients who show evidence of this dementia have adequate memory for personal events, but are unable to name previously familiar objects, people, and places. They show poor language comprehension and experience deficits on verbally-based semantic memory tests such as category fluency and picture naming, as well as on non-verbal tests of semantic memory. The opposite can also occur: Individuals may show evidence of impaired memory for personal episodes while retaining much of their general knowledge about the world (Klein, Loftus, \& Kihlstrom, 2002; Wheeler \& McMillan, 2001).

The existence of these distinct memory systems implies to some that they have evolved via mechanisms of evolution. This argument is plausible. Each of the memory systems captures a different type of information, and retention of each type of information appears to be beneficial to a species.

In humans, these memory systems seem to emerge in at different times in an infant's development. Research on infants' early ability to make sensory discriminations 
suggests that anoetic forms of memory emerge early in individual human development (DeCasper \& Fifer, 1980). Similarly, conceptual knowledge in infants emerges quite early in individual development (Mandler, 2003).

In comparison, it is currently believed that the capacity for episodic memory does not emerge until the beginning of second year of life, at the earliest (Knopf, Mack, \& Kressley-Mba, 2005). The phenomenon of childhood amnesia, in which individuals fail to recall events in their early childhood (Loftus, 1993), is also seen by many as evidence for the late emergence of autonoetic memory. According to Perner and Ruffman (1995), this amnesia is caused by children's inability to represent the experiential origins of one's knowledge. That is, children only gradually attain the mental ability to represent events as things that actually happened to them (as opposed to things that are known). According to Howe and Courage (1993), the construction of such representations can occur only when one has developed a personal identity.

Due to the notion that episodic memory contains specific information about the time and place at which events and behaviors occurred, one might be tempted to link the ability to place events in time exclusively to this memory system. We maintain, however, that this inference would be a mistake. Instead, each of the memory systems can make a contribution to the extent to which an individual knows when an event occurred. Consider how general (noetic) knowledge might aid temporal estimation. Even though an adult individual may not be able to recall specifically the time when she fell out of her high chair, she might reasonably make an inference that the event is old. This can occur because of the general knowledge that babies sit in high chairs. Individuals may use 
anoetic knowledge in their quest for information, as well. They are likely unaware that they sometimes use the strength or vividness of their memory to judge the age of an event, but they seem to do it, nonetheless (Bradburn et al., 1987).

To the extent that the ideas underlying the use of these techniques are valid predictors of an event's age, they can help place events in time. However, they are not infallible. Adults may sometimes sit in high chairs, as when being part of a theatrical performance. The strength or vividness of memories can vary for reasons other than an event's age; one such reason is poorly encoded events.

Such reasoning might suggest that a high level of accuracy in temporal knowledge requires autonoetic knowledge. For example, one of this chapter's co-authors vividly remembers skiing in the Rocky Mountains. When remembering the event, he has visual images of the ski slopes, re-experiences the feeling of a brisk wind in the face, and reexperiences feeling the cold of the snow when a tumble was taken (and when a crown fell off a tooth). These sensations are clues as to when the event occurred: sometime in winter. Moreover, in an attempt to narrow down the range of winters in which the event occurred, the co-author can recall his companions, the purpose of the trip, and how he felt after skiing. This implies that there ought to be a relation between how well one recalls an event and the accuracy with which one can place the event in time - a relation that we have already noted has been oft-supported in the literature.

This line of thought can be extended from the level of the individual to the level of the species. If individuals who possess an autonoetic memory system (containing episodic memories) are better at placing events in time than those who do not possess 
such memories, then those species that possess autonoetic memory systems ought to be better at placing events in time than those that do not. Do any species possess autonoetic memory systems? Which ones? Can these species use these systems to locate specific events in time?

These questions are currently provoking a fair amount of debate. Some theorists (Roberts, 2002; Suddendorf \& Corballis, 1997) have claimed that only humans possess an autonoetic memory system. As evidence for this claim, they note that there is not solid and unequivocal evidence pointing to the idea that non-human species can recall individual and specific events. However, others look at this claim with some skepticism (Eichenbaum, Fortin, Ergorul, Wright, \& Agster, K.L., 2005; Olton, 1984; Zentall, 2005), pointing out that animals often respond as if they had memories for specific events in their lives.

Supporters of the thesis that only humans possess episodic memories would correctly counter by pointing out that temporally sensitive behavior does not necessarily require the presence of an episodic memory system. For example, the behavior of the jays in the Griffiths et al. (1999) research can be explained by a trace-strength mechanism. The jays may have learned that a weak memory trace of meal worm locations implied decayed worms, but a stronger memory trace of meal worm locations implied nondecayed worms. Similar non-episodic mechanisms can be applied to explain the temporal discrimination ability of non-human animals. Such explanations are especially attractive to some because they rely on anoetic knowledge. That is, they can explain the use of prior 
knowledge without the necessity of resorting to higher-order conceptual knowledge (noetic) or episodic knowledge (autonoetic).

However, several recent behavioral experiments suggest the presence of autonoetic knowledge in non-human animals. For example, Mercado, Murray, Uyeyama, Pack, and Herman (1998) trained dolphins to perform a number of complex responses when given arm-gesture commands. Among the commands was one that indicated that the dolphin was to repeat the most recent response. Another command was for the dolphin to execute a novel response (i.e., not something recently done). On probe trials, the dolphins were signaled to execute a novel response, then to repeat the most recent response. To respond correctly, the dolphin must have used its memory for its own prior behavior for the subsequent response - that is, the dolphin must have had the capacity to recall the specific episode encompassed by the initial novel response.

Ultimately, the debate about whether animals have autonoetic knowledge may not be settled by behavioral evidence alone. Neurological analyses are especially relevant to the debate's outcome. Along these lines, Rolls, Xiang, and Franco, (2005) made recordings from single hippocampal formation neurons while macaques performed an object-place memory task. This task required the monkeys to learn associations between objects and where they were shown in a room. The recordings revealed that some neurons responded differently to different objects independently of location; other neurons responded to the spatial view independently of which object was present at the location; while still other neurons responded to a combination of a particular object and the place where it was shown in the room. These results suggest that, in the primate 
hippocampus, there are separate as well as combined representations of objects and their locations in space. Rolls et al. argue that such results are consistent with the presence of an episodic memory system, in which the formation of associations between objects and the places where they are seen is required.

Another study looking at whether episodic memory is neurologically plausible in animals similarly implicated the hippocampus in episodic memory. Ergorul and Eichenbaum (2004) trained rats to remember single training episodes. Each episode consisted of a series of odors presented in different places on an open field. The test task examined whether the rats could recall the order of the presented events. The researchers examined the individual contributions of odor and spatial cues to the rats' order judgments. Normal rats used a combination of spatial ("where") and olfactory ("what") cues to distinguish when events occurred. Moreover, rats with lesions of the hippocampus failed to using combinations of spatial and olfactory cues in these judgments. These data suggest that rats integrate "what," "where," and "when" information in memory for single experiences, and that the hippocampus is critical to this capacity.

While acknowledging that the debate about episodic memory in non-humans is not yet resolved, we admit favoring a hypothesis that is grounded in principles of evolution. As noted earlier, we think that it could be advantageous to a species to have at least some memory for specific life episodes. Hence, given the presence of appropriate genetic material and selection pressures, it strikes us as plausible that such a memory system could have developed in non-humans. Nonetheless, given that the self-concept is much more evolved in humans than in non-humans, and that the evolutionary pressures 
of human environments may favor those who possess temporal knowledge, it also strikes us as reasonable that the human episodic memory system should be more advanced than any similar systems that evolved in non-human animals.

\section{Summary}

In this chapter, we argued that the capacity to retain temporal knowledge about specific events in an individual's life was a trait subjected to the pressures of evolution. Those pressures may have been: (1) environmental, resulting from the need to respond adaptively to the need for optimally regulating activities such as food procurement; (2) social, resulting from the need to establish interpersonal facts, such as infant paternity; and (3) internal, resulting from the needs and requirements of a mental system capable of symbolically representing and manipulating information about the self.

We supported this argument by pointing out that the capacity to possess eventspecific temporal knowledge was not unique to humans, and that some of the same mental mechanisms available for the establishment of temporal knowledge in humans are also available to non-human species. In addition, however, we noted that existing evidence suggests that the capacity to represent and use temporal knowledge is better evolved in humans than in other species. A case in point is the presence of an autonoetic memory system, giving humans especially good access to event-related information that could aid in establishing the time at which an event occurred. A review of the human literature pointed to the use of this information in the reconstruction of temporal knowledge, as well as to the operation of other mental mechanisms involving both anoetic and noetic forms of information. 


\section{References}

Betz, A. L., \& Skowronski, J. J. (1997). Self-events and other-events: Temporal dating and event memory. Memory and Cognition, 25, 701-714.

Bradburn, N. M., Rips, L. J., \& Shevell, S. K. (1987). Answering autobiographical questions: The impact of memory and inference on surveys. Science, 236, 151167.

Bradshaw, C. M., \& Szabadi, E. (Eds.). (1997). Time and behaviour: Psychological and neurobehavioural analyses. In G.E. Stelmach \& P.A. Vroon (Eds.), Advances in psychology, Vol. 120. Amsterdam: Elsevier.

Brown, G. D. A., \& Chater, N. (2001). The chronological organization of memory: Common psychological foundations for remembering and timing. In C. Hoerl, \& T. McCormack, Time and memory: Issues in philosophy and psychology (pp 77 110). Oxford: Clarendon Press.

Brown, G. D. A., Preece, T., \& Hulme, C. (2000). Oscillator-based memory for serial order. Psychological Review, 107, 127-181.

Buckner, R. L., \& Schacter, D. L. (2004). Neural Correlates of Memory's Successes and Sins. In M.S. Gazzaniga (Ed.), The cognitive neurosciences (3rd ed., pp. 739752). Cambridge, MA, US: MIT Press.

Cameron, J. J., Wilson, A. E. \& Ross, M. (2004) Autobiographical Memory and SelfAssessment. In D. R. Beike, J. M. Lampinen, \& D. A. Behrend (Eds.), The self and memory (pp. 207-226). New York, NY: Psychology Press. 
Temporal Knowledge and Autobiographical Memory --- 30

Conway, M. A. \& Pleydell-Pearce, C. W. (2000). The construction of autobiographical memories in the self-memory system. Psychological Review, 107, 261-288.

DeCasper, A. J., \& Fifer, W. P. (1980). Of human bonding: Newborns prefer their mother's voices. Science, 208, 1174-1176.

de Kort, S. R., Dickinson, A., \& Clayton, N. S. (2005). Retrospective cognition by foodcaching western scrub-jays. Learning and Motivation, 36, 159-176.

Eichenbaum, H., Fortin, N. J., Ergorul, C., Wright, S. P., \& Agster, K. L. (2005). Episodic recollection in animals: "If it walks like a duck and quacks like a duck...". Learning and Motivation, 36, 190-207.

Ergorul, C., \& Eichenbaum, H. (2004). The Hippocampus and Memory for "What," "Where," and "When". Learning and Memory, 11, 397-405.

Friedman, W.J. (1987). A follow-up to "Scale effects in memory for the time of events": The earthquake study. Memory and Cognition, 15, 518-520.

Freidman, W. J. (2001). Memory processes underlying humans' chronological sense of the past. In C. Hoerl, \& T. McCormack, Time and memory: Issues in philosophy and psychology (pp 139-168). Oxford: Clarendon Press.

Friedman, W. J. (2004). Time in autobiographical memory. Social Cognition, 22, 591605.

Gallistel, C. R. (1990). The organization of learning. Cambridge, MA: MIT Press.

Gibbons, J. A., \& Thompson, C. P. (2001). Using a calendar in event dating. Applied Cognitive Psychology, 15, 33-44. 
Griffiths, D., Dickinson, A., \& Clayton, N. (1999). Episodic memory: What can animals remember about their past? Trends in Cognitive Sciences, 3, 74-80.

Haddan, A.W. (1872). The works of Aurelius Augustine. A new translation. Edited by the Rev. Marcus Dods. Edinburgh: T. \& T. Clark.

Hodges, J. R., Patterson, K., Oxbury, S., \& Funnell, E. (1992). Semantic dementia: progressive fluent aphasia with temporal lobe atrophy. Brain, 115, 1783-1806.

Hoffding, H. (1885). Outlines of psychology. London: Macmillian.

Hoerl, C., \& McCormack, T. (2001). Time and memory: Issues in philosophy and psychology. Oxford: Clarendon Press.

Howe, M. L., \& Courage, M. L. (1993). On resolving the enigma of infantile amnesia. Psychological Bulletin, 113, 305-326.

James, W. (1890). The Principles of Psychology. New York: Henry Holt.

Klein, S. B., Loftus, J., \& Kihlstrom, K. F. (2002). Memory and temporal experience: The effects of episodic memory loss on an amnesic patient's ability to remember the past and imagine the future. Social Cognition, 20, 353-379.

Knopf, M., Mack, W. \& Kressley-Mba, R. (2005). Knowing and remembering: On episodic memory in infants and preverbal children. Psychologische Rundschau, 56, 113-122.

Loftus, E. F. (1993). Desperately seeking memories of the first few years of childhood: The reality of early memories. Journal of Experimental Psychology: General, 122, 274-277. 
Mandler, J. M. (2003). Conceptual categorization. In D. H. Rakison \& L. M. Oakes (Eds.), Early category and concept development: Making sense of the blooming, buzzing confusion (pp. 103-131). New York, NY: Oxford University Press.

McCormack, T. (2001). Attributing episodic memory to animals and children. In C.

Hoerl, \& T. McCormack, Time and memory: Issues in philosophy and psychology (pp. 285-313). Oxford: Clarendon Press.

Mercado, E., III, Murray, S. O., Uyeyama, R. K., Pack, A. A., \& Herman, L. M. (1998). Memory for recent actions in the bottlenosed dolphin (Tursiops truncatus): Repetition of arbiutrary behaviors using an abstract rule. Animal Learning and Behavior, 26, 210-218.

Ogden, J. A., \& Corkin, S. (1991). Memories of H.M. In W.C. Abraham, M.C. Corballis, \& K.G. White (Eds.), Memory mechanisms: A tribute to G.V. Goddard (pp. 195215). Hillsdale, NJ: Erlbaum.

Olton, D. S. (1984). Comparative analysis of episodic memory. The Behavioral and Brain Sciences, 7, 250-251.

Rolls, E. T., Xiang, J., \& Franco, L. (2005). Object, Space, and Object-Space Representations in the Primate Hippocampus. Journal of Neurophysiology, 94, 833-844.

Rubin, D. E., \& Baddeley, A. (1989). Telkescoping is not time compression: A model of the dating of autobiographical events. Memory and Cognition, 17, 653-661.

Sagarin, B. J. (2005). Reconsidering Evolved Sex Differences in Jealousy: Comment on Harris (2003). Personality and Social Psychology Review, 9, 62-75. 
Saksida, L. M., \& Wilke, D. M. (1994). Time-of-day discrimination by pigeons. Animal Learning and Behavior, 22, 143-154.

Schwartz, B. L., Hoffman, M. L., \& Evans, S. (2005). Episodic-like memory in a gorilla: A review and new findings. Learning and Motivation, 36, 226-244.

Sedikides, C., \& Brewer, M. B. (2001). Individual self, relational self, collective self. Philadelphia, PA: Psychology Press.

Sedikides, C., \& Gregg, A. P. (2003). Portraits of the self. In M. A. Hogg \& J. Cooper (Eds.), Sage handbook of social psychology (pp. 110-138). London: Sage Publications.

Sedikides, C., \& Skowronski, J. A. (1997). The symbolic self in evolutionary context. Personality and Social Psychology Review, 1, 80-102.

Sedikides, C., \& Skowronski, J. J. (2000). On the evolutionary functions of the symbolic self: The emergence of self-evaluation motives. In A. Tesser, R. Felson, \& J. Suls (Eds.), Psychological perspectives on self and identity (pp. 91-117). Washington, DC: APA Books.

Sedikides, C., \& Skowronski, J. J. (2003). Evolution of the self: Issues and prospects. In M. R. Leary \& J. P. Tangney (Eds.), Handbook of self and identity (594-609). New York, NY: Guilford.

Sedikides, C., Skowronski, J. J., \& Dunbar, R. I. M. (in press). When and why did the self evolve? In M. Schaller, J. A. Simpson, \& D. T. Kenrick (Eds.), Frontiers in social psychology: Evolution and social psychology. Philadelphia, PA:

Psychology Press 
Sedikides, C., Skowronski, J. J., \& Gaertner, L. (2004). Self-enhancement and selfprotection motivations: From the laboratory to an evolutionary context. Journal of Cultural and Evolutionary Psychology, 2, 61-79.

Sedikides, C., \& Strube, M. J. (1997). Self-evaluation: To thine own self be good, to thine own self be sure, to thine own self be true, and to thine own self be better. In M. P. Zanna (Ed.), Advances in Experimental Social Psychology, 29, 209-269. New York, NY: Academic Press.

Skowronski, J. J., Betz, A. L., Thompson, C. P., \& Larsen, S. F. (1995). Long-term performance in autobiographical event dating: Patterns of accuracy and error across a two-and-a-half year time span. In A.L. Healy \& L.B. Bourne (Eds.), Learning and memory of knowledge and skills: Durability and specificity (pp. 206-233). Thousand Oaks, CA: Sage Publications.

Skowronski, J. J., Betz, A. L., Thompson, C. P., \& Shannon, L. (1991). Social memory in everyday life: The recall of self-events and other-events. Journal of Personality and Social Psychology, 60, 831-843.

Skowronski, J. J., Ritchie, T. R., Walker, W.R., Betz, A. L., Sedikides, C., Bethencourt, L. A., \& Martin, A. L. (2006). Ordering Our World: The Quest for Traces of Temporal Organization in Autobiographical Memory. Manuscript under review. Skowronski, J. J., \& Sedikides, C. (1999). Evolution of the symbolic self. In D. H. Rosen \& M. C. Luebbert (Eds.), Evolution of the psyche (pp. 78-94). Westport, CT: Greenwood Publishing Croup, Inc. 
Skowronski, J. J., Walker, W. R., \& Betz, A. L. (2003). Ordering our world: An examination of time in autobiographical memory. Memory, 11, 247-260.

Skowronski, J. J., Walker, W. R., \& Edlund, J. E. (2006). How do you feel about it now and when did it happen? Judgments of emotion and judgments of time in autobiographical memory. In L. J. Sanna \& E.C. Chang (Eds.), Judgments over time: The interplay of thoughts, feelings, and behaviors (pp. NNN-NNN). Oxford, UK: Oxford University Press.

Stapel, D. A., \& Koomen, W. (2005). When Less Is More: The Consequences of Affective Primacy for Subliminal Priming Effects. Personality and Social Psychology Bulletin, 31, 1286-1295.

Sturt, M. (1925). The psychology of time. New York: Harcourt, Brace \& Co.

Thompson, C. P., Skowronski, J. J., \& Betz, A. L. (1993). The use of partial temporal information in dating personal events. Memory and Cognition, 21, 352-360.

Thompson, C. P., Skowronski, J. J., Larsen, S. F., \& Betz, A. L. (1996). Autobiographical memory: Remembering what and remembering when. Hillsdale, NJ: Erlbaum.

Thompson, C. P., Skowronski, J. J., \& Lee, D. J. (1988a). Reconstructing the date of a personal event. In M. M. Gruneberg, P. E. Morris, \& N. Sykes (Eds.) Practical aspects of memory: Current research and issues, (pp. 241-246). New York: Academic Press.

Thompson, C. P., Skowronski, J. J., \& Lee, D. J. (1988b). Telescoping in dating naturally-occurring events. Memory and Cognition, 16, 461-468. 
Tulvng, E. (1985). How many memory systems are there? American Psychologist, 40, 385-398.

Wheeler, M. A., \& McMillan, C. T. (2001). Focal retrograde amnesia and the episodicsemantic distinction. Cognitive, Affective, and Behavioral Neuroscience, 1, 22-36.

Zentall, T.R. (2005). Animals may not be stuck in time. Learning and Motivation, 36, 208-225. 